\title{
Effects of Obesity on Mortality and Morbidity in High-Risk Open Heart Surgery Patients
}

\author{
Hulya Yilmaz Ak'; Yasemin Ozsahin'; Mehmet Ali Yesiltas²*; Ismail Haberal'; Baris Sandal'; Mustafa Yildiz; Kerem Erkalp'; Ziya \\ Salihoglu' \\ ${ }^{1}$ Istanbul University-Cerrahpasa, Cardiology Institute, Department of Anesthesiology and Reanimation, Istanbul, Turkey. \\ ${ }^{2}$ Istanbul Bakirkoy Dr. Sadi Konuk Training and Research Hospital, Department of Cardiovascular Surgery, Istanbul, Turkey. \\ ${ }^{3}$ Istanbul University-Cerrahpasa, Cardiology Institute, Department of Cardiovascular Surgery, Istanbul, Turkey. \\ ${ }^{4}$ Istanbul University-Cerrahpasa Faculty of Medicine, Department of Biostatistics, Istanbul, Turkey. \\ ${ }^{5}$ Istanbul University-Cerrahpasa, Cardiology Institute, Department of Cardiology, Istanbul, Turkey.
}

\author{
*Corresponding Author(s): Mehmet Ali YEŞiLTAŞ \\ Consultant, Bakirkoy Dr. Sadi Konuk Training and \\ Research Hospital, Istanbul, Turkey. \\ Tel: +90-212- 414-71-71, Fax: +90-212-414-64-94; \\ Email: dr.maliyes@gmail.com
}

Received: Feb 01, 2021

Accepted: Mar 03, 2021

Published Online: Mar 05, 2021

Journal: Annals of Cardiology and Vascular Medicine

Publisher: MedDocs Publishers LLC

Online edition: http://meddocsonline.org/

Copyright: (C) Yesiltas MA (2021). This Article is distributed under the terms of Creative Commons Attribution 4.0 International License

Keywords: Open heart surgery; Obesity; EuroSCORE.

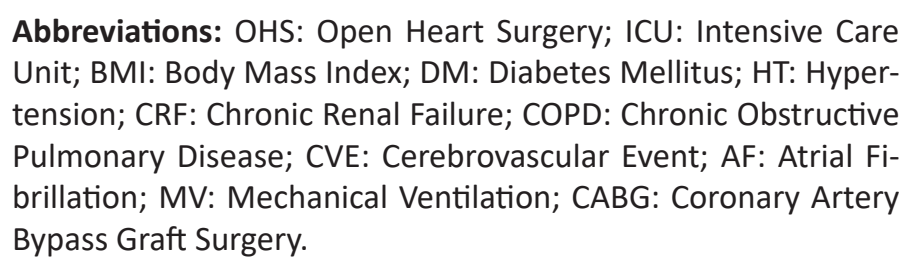

Abbreviations: OHS: Open Heart Surgery; ICU: Intensive Care Unit; BMI: Body Mass Index; DM: Diabetes Mellitus; HT: Hypertension; CRF: Chronic Renal Failure; COPD: Chronic Obstructive Pulmonary Disease; CVE: Cerebrovascular Event; AF: Atrial FiBypass Graft Surgery.

\section{Abstract}

Background: The results of studies on the effect of obesity on mortality and morbidity in cardiac surgery are limited and contradictory. Today, the population of patients referred for open heart surgery is changing, and high-risk patients now represent a significant proportion of surgical candidates. In this study, the effect of obesity on mortality and morbidity in high risk patients in cardiac surgery was investigated retrospectively.

Methods: This study was carried out by retrospectively evaluating the data of patients who had undergone adult Open Heart Surgery (OHS) in a university hospital operating room in the last 5 years (2015-2020). A total of 924 patients were examined in the study. The current online version of EuroSCORE (www.euroscore.org) was used and was calculated separately for all patients. The information in the hospital data system, preoperative evaluation forms, anesthesia follow-up slips, perfusion cards and intensive care, nurse follow-up forms of the patients $(n=95)$ calculated as EuroSCORE $\geq 6$ were examined. The patients were divided into two groups as obese (body mass index (BMI) $\geq 30 \mathrm{~kg} /$ $\mathrm{m}^{2}$ ) and non-obese $\left(\mathrm{BMI}<30 \mathrm{~kg} / \mathrm{m}^{2}\right)$.

Results: In the preoperative data, patients with diabetes mellitus in the obese group were statistically higher than the non-obese group $(p=0.018)$. Mortality rate did not differ according to the groups ( $p>0.05)$.

Conclusion: In this study, no additional negative risk of obesity, which is considered to be an important risk factor for heart diseases, on cardiac surgery was determined.

Cite this article: Hulya Yilmaz AK, Ozsahin Y, Yesiltas MA, Haberal I, Sandal B, et al. Effects of Obesity on Mortality and Morbidity in High-Risk Open Heart Surgery Patients. Ann Cardiol Vasc Med. 2021: 4(1); 1044. 


\section{Introduction}

According to the World Health Organization, obesity is an increasingly global problem affecting $13 \%$ of the world's adult population [1]. Obesity is known to cause many cardiovascular risk factors such as diabetes, hypertension and dyslipidemia, and therefore it is thought to pose a risk for cardiac surgery [2]. However, the results of studies on the effect of obesity on mortality and morbidity in cardiac surgery are limited and contradictory.

Despite all the advances in cardiac surgery, mortality and morbidity after cardiac surgery is still an important problem, especially in patients with additional problems. EuroSCORE is used in the mortality risk estimation in cardiac surgery prepared by Nashef et al. in 1999 and scores of 6 or above in EuroSCORE are accepted as high risk [3]. Today, the population of patients referred for open heart surgery is changing, and high-risk patients now represent a significant proportion of surgical candidates. The reason for this is that medical treatments developed in recent years and advances in interventional cardiology may be associated with the increase in cardiac surgery centers $[4,5]$.

In this study, the effect of obesity on mortality and morbidity in high risk patients in cardiac surgery was investigated retrospectively.

\section{Material and methods}

This study was carried out by retrospectively evaluating the data of patients who had undergone Adult Open Heart Surgery (OHS) in a university hospital operating room in the last 5 years (2015-2020) after obtaining the necessary ethics committee approval (Date: 05.05.2020, number: 74555795-050.01.04). A total of 924 patients were examined in the study. Although the new version of EuroSCORE, EuroSCORE II, has been released, it is recommended to use both versions (Kieser). Although EurOSCORE II, which is the new version of EuroSCORE, has been released, it is recommended that it can be used in both versions [6]. Since EuroSCORE is used in our institution, we preferred this scoring as a risk classification. The current online version of EuroSCORE (www.euroscore.org) was used and was calculated separately for all patients. The information in the hospital data system, preoperative evaluation forms, anesthesia follow-up slips, perfusion cards and Intensive Care (ICU) nurse follow-up forms of the patients $(n=95)$ calculated as EuroSCORE $\geq 6$ were examined. Patients with EuroSCORE $<6$, younger than 18 years old and not using a cardiopulmonary bypass device were not included in the study.

Body Mass Index (BMI) was calculated using the formula weight $(\mathrm{kg}) /$ height $^{2}\left(\mathrm{~m}^{2}\right)$. Using the World Health Organization's obesity classification, the patients were divided into two groups as obese $\left(\mathrm{BMI} \geq 30 \mathrm{~kg} / \mathrm{m}^{2}\right.$ ) and non-obese (BMI $<30 \mathrm{~kg}$ $\left(\mathrm{m}^{2}\right)$. Demographic data, surgical technique, type of operation, Diabetes Mellitus (DM), Hypertension (HT), Chronic Renal Failure (CRF), Chronic Obstructive Pulmonary Disease (COPD), Malignancy, Cerebrovascular Event (CVE), preoperative Atrial Fibrillation (AF) were recorded. Cross-clamp time, bypass time, postoperative AF presence, Mechanical Ventilation (MV) time, Intensive Care (ICU) hospitalization and mortality were record- ed. In addition, 1-year mortality follow-up was performed outside the hospital by examining the death notification system.

\section{Results}

In this study, 95 patients with EuroSCORE 6 and above among 924 patients who underwent OHS in the last 5 years were examined. Four patients were excluded from the study because mortality could not be followed up (Figure 1). A total of 91 patients were studied. The ages of the patients ranged from 20 to 87 (mean = 69.6 \pm 9.7). Of all patients, $49(53.8 \%)$ patients were female, $42(46.2 \%)$ patients were male. The BMI was between 19 and 45 (mean = $28.7 \pm 4.6$ ). Coronary Artery Bypass Graft Surgery (CABG) $(n=32,35.2 \%)$ and Benthall procedure $(n=16,17.6 \%)$ were the most common types of surgery in the high-risk patient group (Table I). The mean cross-clamp time was $124.8 \pm 57.4$ minutes, while the total bypass time was $216.9 \pm 102.8$ minutes. Mean duration of hospitalization in ICU was $146.4 \pm 233.6$ hours. In total, 34 (37.4\%) patients died and the mortality period ranged from 1 to 73 days (mean $=10.2$ \pm 17.6; Table II).There were 59 (64.8\%) patients with a BMI of $<30 \mathrm{~kg} / \mathrm{m}^{2}$ and 32 (35.2\%) patients with a BMI of $30 \mathrm{~kg} / \mathrm{m}^{2}$ in obese and non-obese patients. When the demographic data were examined, no difference was found between the groups in terms of gender $(p>0.05)$. There was no statistically significant difference between the groups with regards to age ( $p>0.05)$. In the preoperative data, patients with DM in the obese group were statistically higher than the non-obese group ( $p=0.018$ ). While there was no difference between the groups in the number of patients with hypertension ( $p>0.05$ ), the patients with COPD were significantly higher in the obese group $(p=0.05)$. CVA, CRF, AF and malignancy rates were similar between groups ( $p>0.05)$. No relationship was found between the groups in the total risk scoring using EuroSCORE ( $p>0.05$ ) (Table III).

There was no significant relationship between the groups in the type of surgery ( $p>0.05)$. No difference was found between the groups in the postoperative AF evaluation ( $p>0.05$ ). Similarly, mortality rate did not differ according to the groups ( $p>0.05)$. A moderate positive correlation was found between the length of stay in ICU and the time of death ( $p=0.002)$. In addition, a weak positive correlation was found between time of death and duration of MV ( $p=0.05)$, and a weak negative relationship between duration of ICU stay and age $(p=0.002)$ (Table III).

\section{Statistical analysis}

SPSS version 21 (IBM Corp. Armonk, NY, USA) software was used for statistical analysis of the data obtained in this study. Two independent groups were examined in the study, the compliance of the data in the groups to the normal distribution was evaluated with the Shapiro-Wilk test, and it was found that they did not meet the necessary conditions. Descriptive statistics were given as frequency, percentage, median, and IQR (Interquartile Range). Pearson Chi-Square test and Fisher's Exact test were used for comparison of categorical data. Mann-Whitney $U$ test was used for intergroup comparisons of continuous variables. Spearman correlation analysis was performed to examine the relationships between variables. $P<0.05$ values were considered significant. 
Table 1: Number of patients according to type of surgeries.

\begin{tabular}{|c|c|c|c|}
\hline Operasyon, n (\%) & Grup $1(n=59)$ & Grup $2(n=32)$ & $\mathbf{P}$ \\
\hline Aortic graft replacement & $3(5,1)$ & $0(0)$ & \multirow{12}{*}{0,09} \\
\hline CABG+CEA & $1(1,7)$ & $1(3,1)$ & \\
\hline$A V R+M V R+T D G$ & $0(0)$ & $1(3,1)$ & \\
\hline CABG+MVR+TVR & $1(1,7)$ & $0(0)$ & \\
\hline AVR & $6(10,2)$ & $1(3,1)$ & \\
\hline BENTHALL & $9(15,3)$ & $7(21,9)$ & \\
\hline CABG & $18(30,5)$ & $14(43,8)$ & \\
\hline$C A B G+A V R$ & $6(10,2)$ & $0(0)$ & \\
\hline CABG+BENTHALL & $5(8,5)$ & $0(0)$ & \\
\hline CABG+MVR & $1(1,7)$ & $3(9,4)$ & \\
\hline MVR & $6(10,2)$ & $2(6,3)$ & \\
\hline MVR+TDG & $3(5,1)$ & $3(9,4)$ & \\
\hline
\end{tabular}

CABG: Coronaryartery Bypass Graft Surgery; CEA: Carotid Endarterectomy; AVR: Aortic Valve Replacement; MVR: Mitral Valve Replacement; TDG: Tricuspid De Vega; TVR: Tricuspid Valve Replacement; BENTHALL: Benthall Procedure.

Table 2: Demographic data of patients.

\begin{tabular}{|c|c|c|}
\hline & Mean \pm SD & N\% \\
\hline Age & $69.6 \pm 9.8$ & \\
\hline BMI $\left(\mathrm{kg} / \mathrm{m}^{2}\right)$ & $28.6 \pm 4.6$ & \\
\hline Height (cm) & $161 \pm 8.3$ & \\
\hline Weight (kg) & $74.7 \pm 13.6$ & \\
\hline $\begin{array}{l}\text { Gender } \\
\text { Male } \\
\text { female }\end{array}$ & & $\begin{array}{l}42(46.2 \%) \\
49(53.8 \%)\end{array}$ \\
\hline $\begin{array}{l}\text { Groups } \\
\qquad \text { Group } 1(B M I<30) \\
\text { Group } 2(B M I \geq 30)\end{array}$ & & $\begin{array}{l}59(64.8 \%) \\
32(35.2 \%)\end{array}$ \\
\hline $\begin{array}{l}\text { Systemic diseases } \\
\qquad D M \\
H T \\
C O P D \\
C V E \\
A F \\
A R F \\
\text { Malignancy } \\
\text { Postoperatif } A F\end{array}$ & & $\begin{array}{c}43(47.3 \%) \\
72(79.1 \%) \\
5(5.5 \%) \\
4(4.4 \%) \\
19(20.9 \%) \\
10(11 \%) \\
3(3.3 \%) \\
16(17.6 \%)\end{array}$ \\
\hline $\begin{array}{l}\text { EuroSCORE } \\
\qquad \begin{array}{l}7 \\
8 \\
9 \\
10 \\
11 \\
12\end{array}\end{array}$ & & $\begin{array}{c}45(49.5 \%) \\
22(24.2 \%) \\
16(17.6 \%) \\
4(4.4 \%) \\
2(2.2 \%) \\
2(2.2 \%)\end{array}$ \\
\hline Cross-Clamp time (min) & $124.9 \pm 57.4$ & \\
\hline Bypass time (min) & $216.9 \pm 102.9$ & \\
\hline Duration of ICU stay (hours) & $146.4 \pm 233.7$ & \\
\hline Duration of MV (hours) & $78.7 \pm 184.1$ & \\
\hline Mortality (day) & & $34(37.4 \%)$ \\
\hline Death time (hour) & $10.2 \pm 17.7$ & \\
\hline
\end{tabular}

BMI: Body Mass Index; DM: Diabetes Mellitus; HT: Hypertension; COPD: Chronic Obstructive Pulmonary Disease; CVE: Cerebrovascular Event; AF: Atrial Fibrillation; CRF: Chronic Renal Failure; ICU: Intensive Care Unit; MV: Mechanical Ventilation.
Table 3: Comparison of groups.

\begin{tabular}{|c|c|c|c|}
\hline n (\%) & Group $1(n=59)$ & Grup $2(n=32)$ & $\mathbf{P}$ \\
\hline \multicolumn{4}{|l|}{ Gender } \\
\hline Male & $31(52.5)$ & $11(34.4)$ & \multirow[t]{2}{*}{0.15} \\
\hline Female & $28(47.5)$ & $21(65.5)$ & \\
\hline \multicolumn{4}{|l|}{ EuroSCORE point } \\
\hline 7 & $27(45.8)$ & $18(56.3)$ & \multirow{6}{*}{0.75} \\
\hline 8 & $16(27.1)$ & $6(18.8)$ & \\
\hline 9 & 11 (18.6) & $5(15.6)$ & \\
\hline 10 & $2(3.4)$ & $2(6.3)$ & \\
\hline 11 & $2(3.4)$ & $0(0)$ & \\
\hline 12 & $1(1.7)$ & $1(3.1)$ & \\
\hline \multicolumn{4}{|l|}{ Type of surgery } \\
\hline Emergency & $3(5.1)$ & $1(3.1)$ & \multirow{2}{*}{1} \\
\hline Elective & 56 (94.9) & 31 (96.9) & \\
\hline \multicolumn{4}{|l|}{ Systemic diseases } \\
\hline DM & $22(37.3)$ & $21(65.6)$ & 0.02 \\
\hline HT & 43 (72.9) & $29(90.6)$ & 0.86 \\
\hline COPD & $1(1.7)$ & $4(12.5)$ & 0.05 \\
\hline CVE & $1(1.7)$ & $3(9.4)$ & 0.12 \\
\hline $\mathrm{AF}$ & $12(20.3)$ & $7(21.9)$ & 0.86 \\
\hline ARF & $5(8.5)$ & $5(15.6)$ & 0.31 \\
\hline Malignancy & $3(5.1)$ & - & 0.55 \\
\hline \multicolumn{4}{|l|}{ Median (IQR) } \\
\hline Age (years) & $71(8)$ & $70.50(14.25)$ & 0.51 \\
\hline Cross-clamp time (minutes) & $110(62)$ & $109(160)$ & 0.92 \\
\hline Bypass time (minutes) & $193(77)$ & $175,50(96)$ & 0.42 \\
\hline ICU stay (days) & 72 (96) & $96(46,75)$ & 0.67 \\
\hline Duration of MV (hours) & $24(72)$ & $24(6)$ & 0.58 \\
\hline Mortality & $23(39)$ & $11(34.4)$ & 0.84 \\
\hline Time of death (days) & $4(6)$ & $3(14.25)$ & 0.97 \\
\hline Postoperative AF & 10 (16.9) & $6(18.8)$ & 0.83 \\
\hline
\end{tabular}

DM: Diabetes Mellitus; HT: Hypertension; COPD: Chronic Obstructive Pulmonary Disease; CVE: Cerebrovascular Event; AF: Atrial Fibrillation; CRF: Chronic Renal Failure; ICU: Intensive Care Unit; MV: Mechanical Ventilation; IQR: Inter Quartile Range.

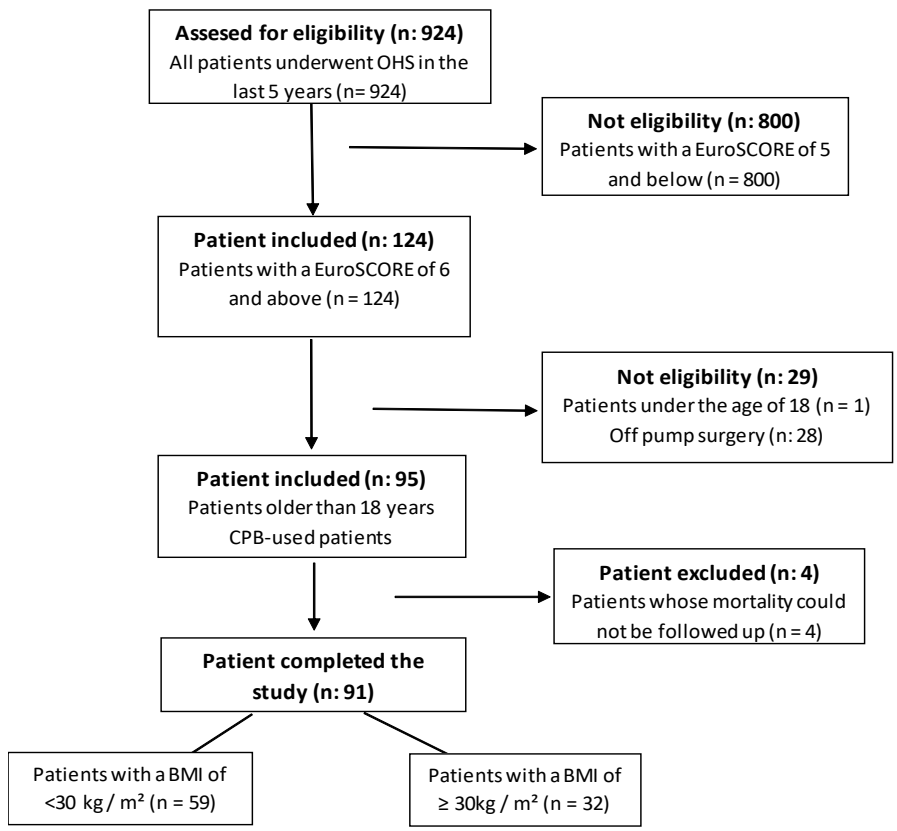

OHS: Open Heart Surgery; CPB: Cardiopulmonary Bypass; BMI: Body Mass Index.

Figure 1: Flow chart of the cohort. 


\section{Discussion}

Obesity is an increasingly important public health problem. BMI is the most widely used unit of measurement in the diagnosis of obesity. The American Heart Association and the World Health Organization define obesity as the condition of having a BMI of $30 \mathrm{~kg} / \mathrm{m}^{2}$ or greater [1]. Although a significant risk increase is expected for anesthesia in obese patients, this situation is not clear enough in cardiac surgery [7]. Although there are insufficient data to support this assumption in obese patients undergoing cardiac surgery, it is thought that obesity increases the perioperative and postoperative risk [8]. EuroSCORE (European System for Cardiac Operative Risk Evaluation), which we prefer to use in our study, is the most used risk scale indicating the risk of cardiac surgery, does not take BMI as a criterion and does not give points for obesity. Parsonnet classification, which is thought to show similar results to EuroSCORE in mortality estimation, gives 3 points for $\mathrm{BMl}>35 \mathrm{~kg} / \mathrm{m}^{2}$ [9]. The Society of Thoracic Surgeons (STS) scoring is also one of the important risk classifications used in cardiac surgery. While this scoring gives 4 points for BMI of $30-40 \mathrm{~kg} / \mathrm{m}^{2}$, it gives 9 points for $\mathrm{BMI}>40 \mathrm{~kg} / \mathrm{m}^{2}$ [10]. APACHE II (Acute Physiology and Chronic Health Evaluation II) scoring system is a globally accepted scoring system for determining the expected mortality rate in ICU units, but BMI is not evaluated in this scoring system [11].

In the study of Kotsis et al. examining the cardiovascular risks of obesity, obesity was associated with hypertension, dyslipidemia and type II diabetes [2]. In this study, while the rate of DM and COPD was higher in the obese patient group, the rates of systemic diseases such as HT, CVA, malignancy and CRF were similar.

In addition to the possibility of difficult intubation and ventilation, obesity also worries anesthesiologists with its negative effects on the lung. Oxygen consumption and carbon dioxide production increase, gas exchange deteriorates, lung compliance decreases, and resistance and respiratory work increase in obese patients compared to those with normal body weight [12]. OHS causes atelectasis, inflammation and microembolism, and impairment in lung structure and function, independent of BMI. However, lung-related problems increase seriously in obese cardiac surgery patients $[13,14]$. Various studies have shown an increased risk of long-term ventilation, reintubation and pulmonary infection in cardiac surgery patients with high BMI $[15,16]$. Most patients are disconnected from after 6-10 hours after OHS. However, this defined period is not clear [17]. The heart surgery guideline published by the Enhanced Recovery After Surgery (ERAS) Association in 2019 recommends extubation within the first 6 hours after surgery [18]. If the MV duration is longer than 24 hours, it is defined as prolonged MV [19]. In our study, MV durations were quite long with an average of 78.7 hours. We attributed this to the high risk patient population of our study. We could not find a relationship between obesity and prolonged MV durations, but more detailed studies are needed for its possible effect.

The frequency of obese patients with cardiac surgery is increasing day by day, which brings to mind the idea of increased surgery cost. Ghanta et al. found that obese and morbidly obese patients progress with greater morbidity, including prolonged ventilation, pneumonia, and kidney failure. Higher BMI was associated with longer ICU stay, length of hospital stay, and higher hospital cost and mortality [20]. The definition of long ICU stay in cardiac surgery is changing. While previous publications define this period as 72 hours or longer, more recent studies ac- cept it as 24 hours or longer [21, 22]. Since high-risk patients were included in our study, the ICU duration was quite long (146.7 hours), but whether obesity has an effect on this period should be evaluated together with other data of the patient.

It has been suggested that obese patients are more susceptible to postoperative $A F$, which is an important complication after OHS and prolongs the stay of ICU [23]. In a meta-analysis, it has been shown that obesity is associated with postoperative AF risk [24]. De Santo et al. suggested that the relationship between postoperative AF and obesity may be related to obstructive sleep apnea syndrome [25]. In our study, the relationship between obesity and postoperative AF was not determined as a feature in the selected patient population.

Although obesity increases the risk of heart disease, there are studies in which obese patients show greater survival after OHS compared to normal-weight individuals. Stamou et al. showed that obese patients who underwent OHS had less postoperative bleeding than normal weight patients. Bleeding may be decreased due to compression of the intrathoracic area due to high mediastinal fat ratio and high abdominal pressure. In the same study, it was shown that mortality rate was lower in obese patients compared to normal weight patients [26]. This paradoxical situation is also encountered in the study of Vargo et al. It has been shown that mortality is lower in obese patients with OHS, but there is an increase in the rate of acute renal failure and wound infection [27]. This condition, called the obesity paradox, can be attributed to the high metabolic reserves and body fat of obese patients. It has been suggested that the reason for this may be the increase in the secretion of amino acids and adipokines, a decrease in B-type natriuretic peptide levels, oxidative stress and inflammation [28]. This paradoxical situation does not mean that obesity is recommended to reduce surgical risks. However, it may partly explain that the expected increase in mortality and morbidity is not that high.

In a prospective study by Burgos et al., it was shown that obesity had no effect on in-hospital and 1-year mortality in patients who recently underwent cardiac surgery. Similarly, in various studies, no increase was observed in the mortality of obese patients who underwent OHS compared to patients with normal weight [29-32]. Similar to these studies, we did not find a significant difference between the mortality of obese patients and those with normal body weight.

\section{Conclusion}

In this study, no additional negative risk of obesity, which is considered to be an important risk factor for heart diseases, on cardiac surgery was determined. This result confirms the reliability of risk scoring systems that do not include BMI, such as EuroSCORE, in predicting mortality and morbidity. In this respect, it appears as very valuable information. Although there are many studies on obesity and cardiac surgery, the number of studies investigating the effectiveness of obesity with risky cardiac surgery patients is very limited. We think that more comprehensive studies on this subject should be included in the literature.

\section{References}

1. https://www.who.int/news-room/fact-sheets/detail/obesityand-overweight.

2. Kotsis V, Jordan J, Micic D, Finer N, Leitner DR, et al . Obesity and cardiovascular risk: a call for action from the European Society of Hypertension Working Group of Obesity, Diabetes and 
the High-risk Patient and European Association for the Study of Obesity: part A: mechanisms of obesity induced hypertension, diabetes and dyslipidemia and practice guidelines for treatment. J Hypertens. 2018; 36: 1427-1440.

3. Nashef SA, Roques F, Michel P, Gauducheau E, Lemeshow S, et al. European system for cardiac operative risk evaluation (EuroSCORE). Eur J Cardiothorac Surg. 1999; 16: 9-13.

4. Stamou SC, Nussbaum M, Stiegel RM, Reames MK, Skipper ER, et al. Effect of body massindex on outcomes after cardiac surgery: Is there an obesity paradox? AnnThoracSurg. 2011; 91: 4247.

5. Stoica SC, Sharples LD, Ahmed I, Roques F, Large SR, et al. Preoperative risk prediction and intraoperative events in cardiac surgery. Eur J Cardiothorac Surg. 2002; 21: 41-46.

6. Abramov D, Tamariz MG, Fremes SE, Guru V, Borger MA, et al. Trends in coronary artery bypass surgery results: A recent, 9-year study. Ann Thorac Surg. 2000; 70: 84-90.

7. Kieser TM, Rose MS, Head SJ. Comparison of logistic EuroSCORE and EurOSCORE II in predicting operative mortality of 1125 total arterial operations. Eur J Cardiothorac Surg. 2016; 50: 509-518.

8. Salihoglu Z, Karaca S, Kose $\mathrm{Y}$, Zengin K, Taskin M. Total intravenous anesthesia versus single breath technique and anesthesia maintenance with sevoflurane for bariatric operations. Obes Surg. 2001; 11: 496-501.

9. Birkmeyer NJ, Charlesworth DC, Hernandez F, Leavitt BJ, Marrin $\mathrm{CA}$, et al. Obesity and risk of adverse outcomes associated with coronary artery bypass surgery. Northern New England Cardiovascular Disease Study Group. Circulation. 1998; 97: 1689-1694.

10. Berman M, Stamler A, Sahar G, Georghiou GP, Sharoni E, et al. Validation of the 2000 Bernstein-Parsonnet score versus the EuroSCORE as a prognostic tool in cardiac surgery. Ann Thorac Surg. 2006; 81: 537-40.

11. Shahian DM, O'Brien SM, Filardo G, Ferraris VA, Haan CK, et al. Society of Thoracic Surgeons Quality Measurement Task Force. The Society of Thoracic Surgeons 2008 cardiac surgery risk models: part 1--coronary artery bypass grafting surgery. Ann Thorac Surg. 2009; 8: S2-22.

12. Knaus WA, Draper EA, Wagner DP, Zimmerman JE. APACHE II: A severity of disease classification system. Crit Care Med. 1985; 13: 818-829.

13. Salihoglu Z, Demiroluk S, Dikmen Y. Respiratory mechanics in morbid obese patients with chronic obstructive pulmonary disease and hypertension during pneumoperitoneum. Eur J Anaesthesiol. 2003; 20: 658-661.

14. Ailawadi G, Chang HL, O'Gara PT, O'Sullivan K, Woo YJ, et al. Pneumonia after cardiac surgery: Experience of the National Institutes of Health/Canadian Institutes of Health Research Cardiothoracic Surgical Trials Network. J Thorac Cardiovasc Surg. 2017; 153: 1384-1391.

15. Nguyen DM, El-Serag HB. The epidemiology of obesity. Gastroenterol Clin North Am. 2010; 39: 1-7.

16. Stephens RS, Whitman GJ. Postoperative Critical Care of the Adult Cardiac Surgical Patient: Part II: Procedure-Specific Considerations, Management of Complications, and Quality Improvement. Crit Care Med. 2015; 43: 1995-2014.

17. Domi R, Laho H. Anestheticchallenges in theobesepatient. Anesth. 2012; 26: 758-65.
18. Trouillet JL, Combes A, Vaissier E, Luyt CE, Ouattara A, et al. Prolonged mechanical ventilation after cardiac surgery: outcome and predictors. J Thorac Cardiovasc Surg. 2009; 138: 948-953.

19. Engelman DT, Ben Ali W, Williams JB, Perrault LP, Reddy VS, et al. Guidelines for Perioperative Care in Cardiac Surgery: Enhanced Recovery After Surgery Society Recommendations. JAMA Surg. 2019; 154: 755-766.

20. A collective Task Force Facilitated by the American College of Chest Physicians, the American Association for Respiratory Care, and the American College of Critical Care Medicine. Evidencebased guidelines for weaning and discontinuing ventilatory support. Respir Care. 2002; 47: 69-90.

21. Ghanta RK, LaPar DJ, Zhang Q, Devarkonda V, Isbell JM, et al. Obesity Increases Risk-Adjusted Morbidity, Mortality, and Cost Following Cardiac Surgery. J Am Heart Assoc. 2017; 6: e003831.

22. Hein OV, Birnbaum J, Wernecke K, England M, Konertz W, et al. Prolonged intensive care unit stay in cardiac surgery: Risk factors and long-term-survival. Ann Thorac Surg. 2006; 81: 880-885.

23. Kapadohos T, Angelopoulos E, Vasileiadis I, Nanas S, Kotanidou $A$, et al. Determinants of prolonged intensive care unit stay in patients after cardiac surgery: A prospective observational study. J Thorac Dis. 2017; 9: 70-79.

24. Vyas V, Lambiase P. Obesity and Atrial Fibrillation: Epidemiology, Pathophysiology and Novel Therapeutic Opportunities. Arrhythm Electrophysiol Rev. 2019; 8: 28-36.

25. Hernandez AV, Kaw R, Pasupuleti V, Bina P, loannidis JP, et al. Association between obesity and postoperative atrial fibrillation in patients undergoing cardiac operations: a systematic review and meta-analysis. Ann Thorac Surg. 2013; 96: 1104-1116.

26. De Santo LS, Esquinas AM. How to delineate obstructive sleep apnea and continuous positive airway pressure link in postoperative atrial fibrillation conundrum? J Crit Care. 2016; 31: 276.

27. Stamou SC, Nussbaum M, Stiegel RM, Reames MK, Skipper ER, et al. Effect of body mass index on outcomes after cardiac surgery: Is there an obesity paradox? Ann Thorac Surg. 2011; 91: 42-47.

28. Vargo PR, Steffen RJ, Bakaeen FG, Navale S, Soltesz EG. The impact of obesity on cardiac surgery outcomes. J Card Surg. 2018; 33: 588-594.

29. Dixon JB, Lambert GW. The obesity paradox a reality that require sex planation and clinical interpretation. Atherosclerosis. 2013; 226: 47-48.

30. Baslaim G, Bashore J, Alhoroub K. Impact of obesity on early outcomes after cardiac surgery: experience in a Saudi Arabian center. Ann Thorac Cardiovasc Surg. 2008; 14: 369-375.

31. Burgos LM, Gil Ramírez A, Seoane L, Espinoza J, Furmento JF, et al. Is the Obesity Paradox in Cardiac Surgery Really a Myth? Effect of Body Mass Index on Early and Late Clinical Outcomes. J Cardiothorac Vasc Anesth. 2020: S1053-0770: 1-3.

32. Lopez-Delgado JC, Esteve F, Manez R, Torrado H, Carrio ML, Rodríguez-Castro D, Farrero E, Javierre C, Skaltsa K, Ventura JL. The influence of body mass index on outcomes in patients undergoing cardiac surgery: does the obesity paradox really exist? PLoS One. 2015; 10: e0118858.

33. Branca P, McGaw P, Light R. Factors associated with prolonged mechanical ventilation following coronary artery bypass surgery. Chest. 2001; 119: 537-546. 